\title{
EchoGéo
}

$12 \mid 2010$

La rue en Asie

\section{Construire et reconstruire}

Jean-Louis Chaléard

\section{OpenEdition}

Journals

Édition électronique

URL : https://journals.openedition.org/echogeo/11915

DOI : 10.4000/echogeo.11915

ISSN : 1963-1197

\section{Éditeur}

Pôle de recherche pour l'organisation et la diffusion de l'information géographique (CNRS UMR 8586)

Référence électronique

Jean-Louis Chaléard, «Construire et reconstruire», EchoGéo [En ligne], 12 | 2010, mis en ligne le 31 mai 2010, consulté le 31 juillet 2021. URL : http://journals.openedition.org/echogeo/11915 ; DOI : https://doi.org/10.4000/echogeo.11915

Ce document a été généré automatiquement le 31 juillet 2021

EchoGéo est mis à disposition selon les termes de la licence Creative Commons Attribution - Pas d'Utilisation Commerciale - Pas de Modification 4.0 International (CC BY-NC-ND) 


\title{
Construire et reconstruire
}

\author{
Jean-Louis Chaléard
}

1 Ce douzième numéro d'ÉchoGéo marque la fin de la troisième année d'existence de notre revue. Elle marque aussi un tournant. Jean Marie Théodat, l'infatigable rédacteur en chef, est appelé à participer à la reconstruction d'Haïti. Il a eu l'occasion dans les numéros précédents d'évoquer l'ampleur de la catastrophe qui a frappé le pays. Si nous regrettons son départ qui nous prive momentanément d'un des éléments majeurs de notre équipe, on ne peut qu'approuver son choix d'aller aider ceux qui souffrent et se réjouir qu'il ait été fait appel à ses compétences pour rebâtir un pays dont il a su si bien nous faire connaître la géographie et partager l'âme.

2 Si Haïti a été parmi les thèmes qui ont fait la une des medias et qui interrogent le scientifique sur une plus longue durée, la question du réchauffement climatique est de celles qui reviennent de manière récurrente sous les feux de l'actualité. Après Copenhague, nous avions laissé la parole à Martine Tabeaud dans la rubrique « Sur le vif ». Cette fois-ci Gérard Beltrando présente un point de vue différent. EchoGéo n'a pas vocation à souffler sur les braises et alimenter les polémiques. Mais il est du devoir d'une revue qui s'attache à aborder de façon rigoureuse des thèmes d'actualité que de laisser s'exprimer les différents points de vue des chercheurs, afin que ceux-ci avancent leurs arguments et que le lecteur puisse prendre position en connaissance de cause, à l'écart des turbulences, des simplifications ou des exagérations médiatiques.

Un des thèmes fortement présent dans ce numéro d'ÉchoGéo est celui des villes. La croissance urbaine accélérée, particulièrement dans les pays du Sud, et les phénomènes de métropolisation marquent le monde actuel. Le V $\mathrm{V}^{\mathrm{e}}$ Forum Urbain Mondial de Rio de Janeiro, qui s'est tenu du 22 au 26 mars 2010, fait partie de ces manifestations majeures qui contribuent à l'avancée de la science sur les villes et à une meilleure appréhension des phénomènes urbains. Les géographes français y étaient représentés. Cet événement international permet à Alexis Sierra et Karine Peyronnie de nous offrir un dossier sur les études en géographie urbaine. C'est l'occasion aussi, à travers deux entretiens avec Yves Daugé, sénateur d'Indre-et-Loire, qui conduisait la délégation française au forum de Rio, et Serge Allou, ancien directeur du GRET, de nous donner leur point de vue d'experts et de praticiens des questions urbaines. Ils apportent des éclairages d'acteurs 
qui peuvent alimenter la réflexion des géographes sur la ville et sa construction aujourd'hui.

4 Retour aux îles et aux Antilles, avec le dossier sur Cuba présenté par Marie-Laure Geoffray et Violaine Jolivet. Les auteures y prennent le contre-pied des analyses en terme de «transition » sur le régime cubain. Continuité dans le changement, avec Raul Castro, dans un pays en proie à une grave crise économique? En tous cas, les émigrés de Floride qui espéraient une chute rapide du pouvoir en place à La Havane en sont pour leurs frais. C'est cette situation qui sert de toile de fond aux articles présentés. Ceux-ci, qu'ils traitent de l'éducation et de la recherche, un des fleurons du régime révolutionnaire, de la politique d'habitat où s'entremêlent différentes conceptions, ou d'une société secrète à La Havane mettent en évidence la complexité des situations. Audelà de l'influence du régime révolutionnaire, ils nous offrent les images d'une société insulaire qui s'adapte et innove.

Le dossier sur la rue en Asie consacré à des métropoles émergentes de Chine et du Vietnam, dans la rubrique "Sur le champ ", renvoie plus aux interrogations du Forum Urbain de Rio qu'à celles de pays marqués par le socialisme comme Cuba. Si l'épisode socialiste a eu des conséquences sur les villes prises comme exemples, les évolutions actuelles les engagent dans des processus communs aux grandes métropoles mondiales. Aborder la rue ce n'est pas seulement s'interroger sur un espace urbain particulier et d'apparence limitée. La rue est vie et mouvement. C'est un espace de la ville et où se construit la ville. Les processus à l'œuvre dans les exemples rencontrés révèlent les dynamiques en cours dans les grandes agglomérations urbaines d'Asie, étroitement liés aux phénomènes de mondialisation et de métropolisation. Mais la mondialisation actuelle ne gomme pas d'un coup les héritages architecturaux et sociaux. À Shanghai, les structures des artères périurbaines restent les mêmes qu'à l'époque des concessions. La rue de Shanghai n'est pas celle de Pékin ni celle d'Ho Chi Minh Ville, au-delà des évolutions communes, et à une autre échelle, l'exemple de trois rues périurbaines de Shanghai montre des dynamismes différenciés.

On ne saurait terminer cet éditorial sans rappeler le décès de Paul Pélissier, qui nous a quittés dans la nuit du 6 au 7 avril; ce que la rédaction d'ÉchoGéo a appris avec une immense tristesse. Il accepta un entretien dans le premier numéro de notre revue, prenant le risque d'associer son nom à une équipe qui se lançait dans une aventure totalement nouvelle pour elle. Nous invitons les lecteurs à revisiter ce texte où il s'exprime en géographe, savant et humaniste, ardent défenseur de l'Afrique, dénonçant l'afro-pessimisme ambiant et les idées reçues de toutes sortes sur ce continent auquel il vouait une passion. Ce texte était pour lui l'occasion de faire partager son expérience aux jeunes générations de géographes, comme il a toujours su si bien le faire dans ses enseignements et ses écrits. Pour nous tous, il est l'occasion de méditer sur ce qu'est le métier de géographe, ses difficultés et ses joies, et le nécessaire engagement citoyen qui l'accompagne. Car si Paul Pélissier fut un grand géographe africaniste, il fut aussi, et cela allait de pair, un homme de cœur et d'engagement. Il va de soi que notre revue ne l'oubliera pas. 